\title{
Energy metabolism in cystic fibrosis
}

\author{
BY A. O'RAWE \\ The Nuffield Department of Child Health, The Queen's University of Belfast, Institute of Clinical \\ Science, Grosvenor Road, Belfast BT12 6BJ
}

Cystic fibrosis (CF) remains a major cause of refractory malnutrition in clinical practice. It is clinically and genetically a heterogeneous disorder, and energy metabolism, as with other manifestations of the disease, is subject to wide variability. Differences in metabolic needs are related to the specific CF genotype, and are the result of a complex interaction of physiological, environmental and genetic variables.

Based on the recognition of malnutrition as a major prognostic factor adversely affecting survival, the achievement and maintenance of energy balance in CF is one of the central aims of management. Despite advances in pancreatic supplements and aggressive nutritional support, however, growth retardation of affected children and wasting of $\mathrm{CF}$ adults remains a major clinical problem, evidence of our incomplete understanding of the mechanisms and management of metabolism in the disease.

The prevalence of CF, approximately 5000 in 1985 (British Paediatric Association Working Party on Cystic Fibrosis, 1988), is increasing every year, the increased numbers almost entirely being accounted for by patients over 15 years old. The evolving natural course of $\mathrm{CF}$ as it becomes a condition of adulthood, provides a further source of variation in defining and meeting the metabolic needs of $\mathrm{CF}$ patients. This enlarging population includes an increasing number of adults, a proportion of whom have undergone heart-lung transplant and in whom regulation of metabolism may be related to survival, and also includes presymptomatic infants identified by newborn screening, in whom the importance of adequate nutrition is apparent from the deficits in body composition.

\section{THE NATURE OF THE ENERGY DEFICIT IN CF}

As CF patients comprise a group of malnourished individuals in whom recognized metabolic disturbances exist, it is reasonable to assume that the relative proportions of the body components may be altered. Autopsy studies on the body composition of infants dying with $\mathrm{CF}$ show findings similar to those of malnourished infants dying from other causes (Lloyd-Still, 1976). Accurate measurements of body composition in vivo are necessary to determine the nature of the energy deficit, to establish optimal feeding regimens by ensuring appropriate reconstitution of body fat and lean body mass (LBM) and provide an important reference for comparison of rates of energy expenditure among individuals.

Comparison between methods of measurement of body composition in $\mathrm{CF}$ has demonstrated the inappropriateness of prediction equations for body fat from skinfold thickness (Johnston et al. 1988). The use of either total body potassium measurements or of the deuterium-dilution method have been preferred (Newby et al. 1990). Widespread use of these methods is limited either by cost or availability, but reported studies (Shepherd et al. 1989; Greer et al. 1991) have demonstrated a decrease in both body fat 
and LBM. Protein-energy supplementation has been shown to produce catch-up weight gain with evidence of accretion of LBM in the process (Shepherd et al. 1983).

Important early nutritional deficits have been documented following neonatal screening (Greer et al. 1991) with subclinical nutritional disturbances indicating an energy deficit before the onset of symptoms. Inadequate accretion of total body $\mathrm{K}$ and, thus, body cell mass (BCM), has been shown in some presymptomatic infants detected by screening, and in CF patients growing within normal centiles (Shepherd et al. 1989). Of $161 \mathrm{CF}$ subjects studied, almost one-third of patients had a total body $\mathrm{K}$ less than two standard deviations below the mean for age and sex, whereas only $10-15 \%$ were less than the tenth percentile for weight.

Growth retardation in CF has been attributed to inadequate nutrition and, with the demonstration of similar genetic growth potential in CF and healthy control subjects (Mearns, 1980), it is suggested that growth delay in CF should be largely preventable. However, the finding of deficits in BCM in presymptomatic infants diagnosed by neonatal screening, not only has serious implications for the outcome and management in the early phases of CF, but also supports the suggestion of a basic increase in metabolic demand operating possibly even before birth, at least in some patients, and reports of reduced mean birth weight in CF infants (Dodge \& Yassa, 1980), lends further support to this hypothesis. Furthermore, it has been shown that other genes adjacent to the CF locus may have a major impact on growth, even in patients with the same genotype (Wulbrand et al. 1991).

\section{PATHOGENESIS OF ENERGY EXPENDITURE IN CF}

A number of studies have confirmed that a state of negative energy balance may exist in subjects with CF. Many find it hard to maintain an adequate energy intake because of anorexia associated with the presence of infection, and overall energy intakes may be reduced to $80 \%$ or less of the recommended daily allowance. In addition, despite improved pancreatic enzyme replacement, and even with adjuvant therapy, faecal energy losses may remain as high as $10-20 \%$ of energy intake (Murphy et al. 1991). Differences in body composition will influence measured increases in resting metabolic rate (RMR); however, there are also a number of factors which contribute to an increased energy expenditure in the disease. (1) An important contribution from declining lung function has been recognized (Vaisman et al. 1987). (2) Mutations in the nucleotide-binding fold of the CF protein exert an influence on RMR (O'Rawe $e t$ al. 1991). (3) There may be a role for tumour necrosis factor (TNF) and other cytokines mediating the inflammatory process in inducing nutritional deficits in CF. Plasma TNF is increased during infective exacerbations of CF due to Pseudomonas aeruginosa and does not return to normal following therapy (Elborn et al. 1990). It would seem probable that raised levels of TNF in CF will exert some effect on host intermediary metabolism.

Several studies have examined the level of resting energy requirement in CF patients. The RMR in a group of seventy-one CF patients was shown to be higher than in their peers (Vaisman et al. 1987). However, whilst a decline in pulmonary function was correlated with this increase, a wide range of RMR were seen at all levels of pulmonary function. Furthermore, it was noted that whilst RMR increased with deteriorating lung disease, the RMR in the CF patients studied was higher than normal even when pulmonary function was normal. Investigation of RMR in twenty-three CF patients of 


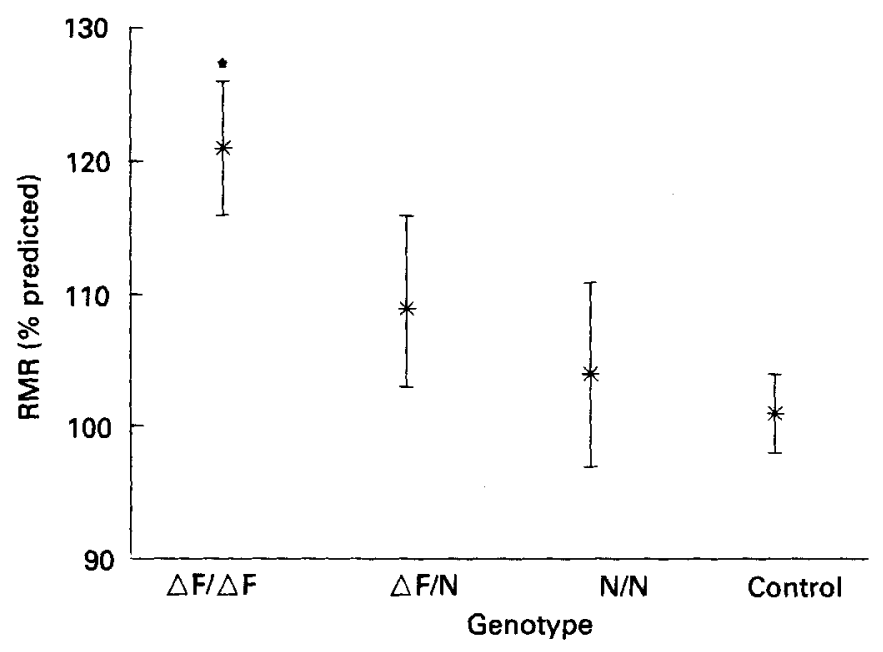

Fig. 1. Influence of genetic mutation on resting metabolic rate in seventy-eight unrelated cystic fibrosis patients grouped according to genotype and in thirty healthy controls. $\triangle \mathrm{F} / \triangle \mathrm{F}, \triangle \mathrm{F} 508$ homozygotes $(n 31) ; \Delta \mathrm{F} / \mathrm{N}$, $\triangle \mathrm{F} 508$ heterozygotes ( $n$ 29); N/N, other mutations ( $n$ 18); controls $(n 30)$. Values are means with $95 \%$ confidence intervals represented by vertical bars.

* Mean value was significantly different from the other genotypes and the controls $(P<0 \cdot 005)$.

slightly younger age-group and with less severe pulmonary disease (Buchdahl et al. 1988) found that even when expressed as a function of lean body mass, RMR remained $7 \cdot 2 \%$ higher in CF patients compared with controls. Correlations between increased RMR and pulmonary function were low in this study group, there being some subjects with high RMR and normal pulmonary function. It was suggested that a basic energy-requiring defect in the CF cell might be contributing to the heightened energy requirements, and a later study using the doubly-labelled-water method to assess total energy expenditure (TEE) in nine well CF infants (Shepherd et al. 1988) appeared to support this. The discovery of the CF gene (Rommens et al. 1989) provided the opportunity to examine influence of genotype on clinical phenotype, and the practical implications of genetic discoveries continue to be explored.

In a study of RMR in seventy-eight unrelated CF patients whose body size, percentage body fat and mean arm muscle circumference did not differ significantly from thirty healthy controls, $59 \%$ of patients had an elevated RMR, the remainder falling within control values. When the patients were grouped according to genotype, the precise nature of the CF mutation was found to exert a profound influence on RMR. Patients homozygous for the delta-F508 mutation (Fig. 1) had a significantly higher RMR (121\% predicted, $95 \%$ confidence interval 116,126) compared with other genotypes and controls $(P<0.005$; O'Rawe et al. 1991). This provided compelling evidence for the existence of a wide variation in the level of energy expenditure in CF, which was influenced by genotyope and which may be ultimately mediated by the basic biochemical defect.

\section{TOTAL ENERGY EXPENDITURE IN CF}

A reliable estimate of energy expenditure is important in tailoring appropriate nutrition in CF patients. A $24 \mathrm{~h}$ period of measurement is the best standard for the measurement 
of energy expenditure, taking into account circadian variation and the marked natural variability in substrate oxidation rate as a person's activities, emotions etc. vary.

Measurements of TEE and determination of physical activity level were made in a group of thirty mild and moderately affected CF patients aged 6-26 years (O'Rawe et al. 1991). TEE was measured in free-living individually calibrated subjects, using the minute-by-minute heart-rate method (HR TEE), over a 2-3 d period (Livingstone et al. 1990). Simultaneous assessment was made in four subjects over a $15 \mathrm{~d}$ period by the doubly-labelled-water method, with HR TEE monitoring over $7 \mathrm{~d}$. The percentage difference in estimates of TEE between the two methods varied from a $10 \%$ overestimate to an estimate $7 \%$ below that from HR TEE. Physical activity levels in CF patients, irrespective of age-group and sex, showed no significant difference from those of healthy children, despite the mild to moderate pulmonary dysfunction demonstrated in the patient group (forced expiratory volume in $1 \mathrm{~s}$, mean 82 (SD 25)\% predicted; forced vital capacity, mean 88 (SD 19)\% predicted). It was concluded that the careful application of HR TEE method is of value in prescribing appropriate energy intake in CF patients, and results indicate that CF patients, including those with moderate levels of pulmonary compromise, maintain levels of physical activity comparable with healthy controls.

\section{CF TRANSMEMBRANE CONDUCTANCE REGULATOR (CFTR) ENERGY METABOLISM AND ION TRANSPORT IN CF}

The influence of genetic variables on metabolism is well recognized. In CF the variable clinical course has been attributed at least in part to specific genotypes at the CF locus. We have suggested a genetic influence on energy expenditure in CF recognizing two clinical subgroups of CF patients, those with increased RMR and those whose RMR is normal.

The common CF mutation (Delta-F508) identified in $71 \%$ of CF chromosomes in the UK (Shrimpton et al. 1991), involves a phenylalanine deletion at position 508 of the gene product and is located in a proposed nucleotide-binding fold. On the basis of structural homology with other proteins (i.e. proteins responsible for the energy-dependent efflux of cytotoxic drugs from cells and the P glycoproteins), a tentative structure for the CFTR has been deduced (Fig. 2); Ringe \& Petsko, 1990). The cytosolic domain (proposed to comprise about $80 \%$ of the protein), is composed of a highly charged R domain, which has sixteen potential sites for phosphorylation, and two nucleotide-binding folds. Recent studies with synthetic oligopeptides, demonstrate that this region binds adenine nucleotides, and it is predicted, using circular dichroism spectroscopy, that the phenylalanine deletion at position 508 would disrupt a beta sheet structure in this region (Thomas et al. 1991). It has been assumed that bound ATP is hydrolysed and the energy released to permit a conformational change in the molecule. Other mutations in the nucleotide-binding fold may also have a disruptive effect on ATP binding. The suggestion that CFTR is a tightly regulated chloride channel and that ATP binding and hydrolysis is necessary for conformational change before $\mathrm{Cl}^{-}$transport (Kartner et al. 1991), is supported by finding that specific mutations in the nucleotide-binding domain altered cellular energy requirement. Conversely, certain known mutations probably not involved in nucleotide-binding do not confer an increase in RMR. These findings are consistent with our present structural and functional knowledge of the gene product (O'Rawe et al. 1991). 


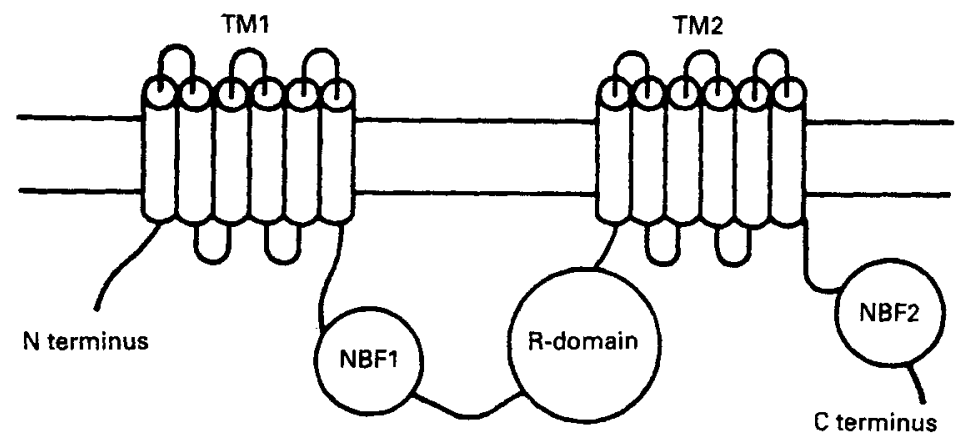

Fig. 2. Schematic model of the cystic fibrosis gene product based on sequence analysis. The segments are transmembrane (TM1, TM2), nucleotide-binding domains (NBF1, NBF2) and domain containing the phosphorylation sites (R). The 'common' $\triangle F 508$ mutation (phenylalanine deletion) occurs in NBF1, Reproduced from Ringe \& Petsko (1990) with permission.

Although the basic biochemical defect in CF remains unknown, the demonstration of (1) altered molecular characteristics affecting both $\mathrm{Cl}^{-}$and sodium channels in $\mathrm{CF}$ (Cotton et al. 1987), (2) evidence of increased mitochondrial calcium uptake and oxygen consumption in CF skin fibroblasts (Feigal \& Shapiro, 1979), (3) in two-threefold elevation in ouabain-sensitive $\mathrm{O}_{2}$ consumption in CF respiratory epithelium (Stutts et al. 1986) and (4) increased turnover of essential fatty acids in erythrocytes of CF patients and carriers (Rogiers et al. 1984) are consistent with the existence of a greater metabolic capacity in CF cells.

The finding of enhanced $\mathrm{Na}$ absorption in $\mathrm{CF}$ nasal epithelium will increase the energy cost of $\mathrm{Na}-\mathrm{K}$ pump activity required to maintain cellular ion gradients. This normally accounts for $20 \%$ or more of the total in vitro energy expenditure of a variety of tissues (Swaminathan et al. 1989). The concept of Ca regulation of mitochondrial dehydrogenase activity and other regulatory enzymes of intermediary metabolism, provides a further link in the regulation of energy metabolism. However, whilst it is certain that a rise in cytosolic $\mathrm{Ca}$ has many results including activation of intermediary metabolism, it is not known, however, whether such disturbances in cell $\mathrm{Ca}$ in $\mathrm{CF}$ are cause or consequence. It is not known whether abnormalities of essential fatty acid (EFA) turnover in CF are a primary or secondary phenomenon. Lipids and proteins interact with each other in biological membranes, and EFA have various roles in cell membrane function and structure. Lipids have been shown to have a regulatory effect on ion pumps, specifically the $\mathrm{Na}^{+} / \mathrm{K}^{+}$-transporting ATPase (EC 3.6.1.37) pump (Yeagle, 1989), there is experimental evidence for protein participation in transmembrane movement of lipids (Kawashima \& Bell, 1987), itself an ATP-dependent process, and membrane phospholipids are involved in the regulation of membrane protein function (Yeagle, 1989).

Although the details of ion-transporting abnormalities in CF epithelium are now known, and interactions between membrane phospholipids and membrane proteins are recognized, how they interact (in processes which may be energy requiring), and the connection between these and other fuctional abnormalities in CF and genetic defect are not known. 


\section{CONCLUSION}

Altered energy metabolism in CF is multi-factorial in aetiology and widely variable in magnitude. There is compelling evidence both from indirect calorimetry and in vitro experiments that CF cells may exhibit a greater metabolic capacity, and we identify specific genotypes as being at greater risk of nutritional compromise. The aim of nutritional management in CF, i.e. to achieve optimal weight gain, ensure appropriate reconstitution of LBM and body fat and, thus, promote well-being and longevity involves (1) precise definition of the events influencing metabolism in CF, (2) dietary manipulation based on needs and losses which are determined by digestive and absorptive phase anomalies, (3) realistic methods to enable the individual to achieve prescribed needs and (4) accurate measurements of body composition to evaluate long-term changes in energy balance. There may also be differences in metabolic response to nutritional support which are related to the specific CF genotype.

In planning nutritional strategies, with a view to normalizing growth and nutritional status as early as possible after diagnosis, the extra daily requirements for both energy and protein will depend both on the initial deficits and on the achievable rate of rehabilitation, preferably by non-invasive methods. It has been shown that energy intake can be enhanced and weight gain sustained for at least 4 years in CF patients using a 'normal' diet in large amounts (Luder et al. 1989). There is no single optimal supplement for use in CF patients. Evidence suggests that high-fat consumers have a high energy intake in comparison with low-fat consumers, at least in the short term (Tremblay et al. 1989); however, an increased level of free fatty acids has been shown to be accompanied by glucose tolerance. Although carbohydrates are generally well tolerated in CF, $50 \%$ of CF patients with exocrine pancreatic insufficiency have biochemical evidence of glucose intolerance and intensive nutritional therapy may unmask latent diabetes.

New questions are emerging from the increased longevity in CF. A possible adverse effect of abnormal glucose metabolism on the prognosis of CF patients has been suggested which warrants careful prospective study (Knowles et al. 1986). Furthermore, as evidence accumulates that events in early life, including infant feeding practices, can have long-term effects on health and disease (Chandra, 1989), it is possible that present feeding practice relating to $\mathrm{CF}$ infants, in whom increased intestinal permeability has been recognized (Leclercq-Foucart et al. 1987), could increase exposure of the enteric immune system to lumen antigens, leading to enhanced or altered immune responses against dietary and microbial antigens later in life. Defining and meeting the metabolic needs of $\mathrm{CF}$ patients provides us with a continuing challenge.

The author was supported by the British Paediatric Association and Cow \& Gate Research Fellowship. Thanks are due to Professor J. Dodge, Dr. K. McKracken, Dr. B. Livingstone, Dr. P. Davies, Dr. I. McIntosh, Dr. A. Redmond, Ms J. Thomson, Mrs. B. Martin and Dr. F. Stanford and to the subjects and their families for their enthusiastic co-operation.

\section{REFERENCES}

British Paediatric Association Working Party on Cystic Fibrosis (1988). Cystic Fibrosis in the United Kingdom 1977-85: an improving picture. British Medical Journal 297, 1599-1602. 
Buchdahl, R. M., Cox, M., Fulleylove, C., Marchant, J. L., Tomkins, A. M., Brueton, M. J. \& Warner, J. O. (1988). Increased resting energy expenditure in cystic fibrosis. Journal of Applied Physiology 64, 1810-1816.

Chandra, R. K. (1989). Long term health implications of mode of infant feeding. Nutritional Research 9, 1-3.

Cotton, C. U., Stutts, M. J., Knowles, M. R., Gatzy, J. T. \& Boucher, R. C. (1987). Abnormal apical cell membrane in cystic fibrosis respiratory epithelium. An in vitro electrophysiological analysis. Journal of Clinical Investigation 79, 80-85.

Dodge, J. A. \& Yassa, J. G. (1980). Food intake and supplementary feeding programmes. Proceedings of the 9th International Congress on Cystic Fibrosis, pp. 125-136. Toronto: The Imperial Press Ltd.

Elborn, J. S., Norman, D., Rayner, R., Hiller, E. J. \& Shale, D. J. (1990). Plasma tumour necrosis factor alpha in cystic fibrosis. Proceedings of the Cystic Fibrosis Research Workers Conference, Warwick, Abstr. $1: 9$.

Feigal, R. J. \& Shapiro, B. L. (1979). Mitochondrial calcium uptake and oxygen consumption in cystic fibrosis. Nature 278, 276-277.

Greer, R., Shepherd, R., Cleghorn, G., Bowling, F. G. \& Holt, T. (1991). Evaluation of growth and changes in body composition following neonatal diagnosis of cystic fibrosis. Journal of Paediatric Gastroenterology and Nutrition 13, 52-58.

Johnston, J. L., Leong, M. S., Checkland, E. G., Zuberbuhler, P. C., Conger, P. R. \& Quinney, H. A. (1988). Body fat assessed from body density and estimated from skinfold thickness in normal children with cystic fibrosis. American Journal of Clinical Nutrition 48, 1362-1366.

Kartner, N., Hanrahan, J. W. \& Jensen, T. J. (1991). Expression of the cystic fibrosis gene in non-epithelial invertebrate cells produces a regulated anion conductance. Cell 64, 681-691.

Kawashima, Y. \& Bell, R. M. (1987). Assembly of the endoplasmic reticulum phospholipid bilayer. Transporters for phosphatidylcholine and metabolites. Journal of Biological Chemistry 262, 16495-16502.

Knowles, M. R., Stutts, M. J., Yankasas, J. R., Gatzy, T. J. \& Boucher, R. C. (1986). Abnormal respiratory epithelial ion transport in cystic fibrosis. Clinical Chest Medicine 7, 285-297.

Leclercq-Foucart, J., Forget, P. P. \& Van Cutsem, J. L. (1987). Lactulose-rhamnose intestinal permeability in children with cystic fibrosis. Journal of Paediatric Gastroenterology and Nutrition 6, 66-70.

Livingstone, M. B. E., Prentice, A. M., Coward, W. A., Ceesay, S. M., Strain, J. J., Nevin, G. B., Barker, M. E. \& Hickey, R. J. (1990). Simultaneous measurement of free-living energy expenditure by the doubly labelled water method and heart-rate monitoring. American Journal of Clinical Nutrition 52, 59-65.

Lloyd-Still, J. D. (1976). Clinical studies on the effects of malnutrition during infancy on subsequent physical and intellectual development. In Malnutrition and Intellectual Development, pp. 103-159 [J. D. Lloyd-Still, editor]. Lancaster: MTP Press Ltd.

Luder, E., Kattan, M., Thornton, J. C., Koehler, K. M. \& Bonforte, R. J. (1989). Efficacy of a non-restricted fat diet in patients with cystic fibrosis. American Journal of Disease of Childhood 143, 458-464.

Mearns, M. B. (1980). The heights of CF patients aged 2-9 years allowing for parental height and severity of pulmonary episodes from birth. In Perspectives in Cystic Fibrosis, pp. 262-265 [J. M. Sturgess, editor]. Toronto: The Imperial Press Ltd.

Murphy, J. L., Wooton, S. A., Bond, S. A. \& Jackson, A. A. (1991). Energy content of stools in normal healthy controls and patients with cystic fibrosis. Archives of Disease in Childhood 66, 495-500.

Newby, M. J., Keim, N. L. \& Brown, D. L. (1990). Body composition of adult cystic fibrosis patients and control subjects as determined by densitometry, bioelectrical impedance, total-body electrical conductivity, skinfold measurements, and deuterium oxide dilution. American Journal of Clinical Nutrition 52, $209-213$.

O'Rawe, A., McIntosh, I., Dodge, J. A., Brock, D. J. H., Redmond, A. O. B., Ward, R. \& Macpherson, A. J. S. (1991). Increased energy expenditure in cystic fibrosis is associated with specific mutations. Clinical Science (In the Press).

Ringe, D. \& Petsko, G. A. (1990). Cystic Fibrosis. A transport problem? Nature 346, 312-313.

Rogiers, V., Dab, I., Michotte, Y., Vercruysse, A., Crokart, R. \& Vis, H. L. (1984). Abnormal fatty acid turnover in the phospholipids of the red blood cell membranes of cystic fibrosis patients (in vitro study). Paediatric Research 18, 704-709.

Rommens, J. M., Iannuzzi, M. C., Kerem, B.-S., Drumm, M. L., Melmer, G., Dean, M., Rozmahel, R., Cole, J. L., Kennedy, D., Hidaka, N., Zsiga, M., Buchwald, M., Riordan, J. R., Tsui, L.-S. \& Collins, F. S. (1989). Identification of the cystic fibrosis gene: chromosome walking and jumping. Science 245 , 1059-1065.

Shepherd, R. W., Holt, T. L., Greer, R., Cleghorn, G. J. \& Thomas, B. J. (1989). Total body potassium in cystic fibrosis. Journal of Paediatric Gastroenterology and Nutrition 9, 200-205. 
Shepherd, R. W., Holt, T. L., Vasques-Velasquez, L., Coward, W. A., Prentice, A. \& Lucas, A. (1988). Increased energy expenditure in young children with cystic fibrosis. Lancet $\mathbf{i}, 1300-1303$.

Shepherd, R. W., Thomas, B. J., Bennett, D., Cooksley, W. G. E. \& Ward, L. C. (1983). Changes in body composition and muscle protein degradation during nutritional supplementation in nutritionally growthretarded children with cystic fibrosis. Journal of Paediatric Gastroenterology and Nutrition 2, 439-446.

Shrimpton, A. E., McIntosh, 1. \& Brock, D. J. H. (1991). The incidence of different cystic fibrosis mutations in the Scottish population: effects on prenatal diagnosis and genetic counselling. Journal of Medical Genetics (In the Press).

Stutts, M. J., Knowles, M. R., Gatzy, J. T. \& Boucher, R. C. (1986). Oxygen consumption and ouabain binding sites in cystic fibrosis nasal epithelium. Paediatric Research 20, 1316-1320.

Swaminatham, R., Chan, E. L. P., Sin, L. Y., King, N. S., Fun, N. S. \& Chan, A. Y. S. (1989). The effect of ouabain on metabolic rate in guinea-pigs: estimation of energy cost of sodium pump activity. British Journal of Nutrition 61, 467-473.

Thomas, P. J., Shengbagamurthi, P., Ysern, X. \& Pedersen, P. L. (1991). Cystic fibrosis transmembrane conductance regulator. Nucleotide binding to a synthetic peptide. Science 251, 555-557.

Tremblay, A., Plourde, G., Despres, J. P. \& Bouchard, C. (1989). Impact of dietary fat content and fat oxidation on energy intake in humans. American Journal of Clinical Nutrition 49, 799-805.

Vaisman, N., Pencharz, P. B., Corey, M., Canny, G. J. \& Hahn, E. (1987). Energy expenditure of patients with cystic fibrosis. Journal of Paediatrics 111, 496-500.

Wulbrand, U., Dork, T., Tummler, B. \& Krawczak, M. (1991). Genetic determinants in cystic fibrosis. Lancet $337,623$.

Yeagle, P. L. (1989). Lipid regulation of cell membrane structure and function. FEBS Journal 3, $1833-1842$. 